\title{
Actoprotector activity of humic acids low-mire wood-grass peat
}

\author{
Logvinova L.A. ${ }^{1}$, Zykova M.V. ${ }^{1}$, Gostyukhina A.A. ${ }^{2}$, Zamoshchina T.A. ${ }^{1,2}$, Tsupko A.V. ${ }^{1}$, \\ Belousov M.V. ${ }^{1}$ \\ ${ }^{1}$ Siberian State Medical University, Tomsk, Russia, ludmila_logvinova@mail.ru \\ ${ }^{2}$ Siberian Federal science-clinical center of Federal microbiological agency, Tomsk, Russia
}

doi: 10.36291/HIT.2019.logvinova.094

Humic acids (HAs) positively affect many body systems: excretory, digestive, nervous. In a few studies, the effect of HAs on the activity of the cardiovascular system is proved [Zykova, 2017; Lasukova, 2018]. With pathology of the heart and blood vessels, which annually take the lives of about 17 million people, there is a decrease in exercise tolerance due to the development of hypoxia. Due to the high mortality from cardiovascular disease, it is important to investigate the actoprotective activity of HAs.

Materials and methods. HAs were isolated by alkaline extraction from sample of lowland wood-grass peats collected from «Tagan» deposit of Tomsk region [Zykova, 2013]. Physicochemical study of HAs carried out [Zykova, 2013]. Bioactivity of HAs was tested on 40 utbred male rats "Wistar" 250-300 g in autumn. The animals were divided on 4 groups of 10 animals each (Table 1). Solution of $\mathrm{NaCl}$ and $\mathrm{HAs}$ was administered intragastrically to experimental animals before $30 \mathrm{~min}$ swimming at the rate of $0.5 \mathrm{ml}$ per $100 \mathrm{~g}$ of mass. As forced exercise used a forced swimming test [Pat. 2617206]. Upon completion of the five-day testing, all animals were withdrawn from the experiment by simultaneous decapitation under $\mathrm{CO}_{2}$-anesthesia. Decapitated animals collected blood to obtain serum. To assess the level of glycolytic processes during exercise, the rat serum lactate content was determined [Brancaccio, 2010; Brooks, 1999]. The concentration of lactate in the serum of the experimental and intact groups was determined by the colorimetric method [Dolgova, 2012; Kamyshnikov, 2000].

Table 1. The distribution of animals in groups

\begin{tabular}{lcccc}
\hline Group of animals & $\begin{array}{c}\text { Living } \\
\text { conditions }\end{array}$ & $\begin{array}{c}0.9 \% \mathrm{NaCl} \\
\text { intragastricall }\end{array}$ & $1 \% \mathrm{HAs}$ & Swimming test \\
\hline Intact & daylight & - & - & - \\
\hline Control No 1 & daylight & - & - & + \\
\hline Control No 2 & daylight & + & - & + \\
\hline Experimental group & daylight & - & + & + \\
\hline
\end{tabular}

Results and discussion. The use of the HAs solution and the presentation of physical exercise to rats in the form of a swimming test until they were completely tired during the 5 days of the experiment contributed to their performance (Table 2). Determining the degree of change in endurance showed an increase of $24-39 \%$ by the last day of testing.

Table 2. The effect of the HAs on the performance of rats in a swimming test

\begin{tabular}{lccccc}
\hline Group of animals/Swimming days & \multicolumn{5}{c}{ Intact duration (s) } \\
\hline & 1 & 2 & 3 & 4 \\
Intact & \multicolumn{5}{c}{ Did not swim } \\
\hline Control No 1 & 38 & 46 & 53 & 52 & 47 \\
\hline Control No 2 & 64 & 61 & 65 & 69 & 63 \\
\hline Experimental group & 70 & 76 & 101 & 97 & 97 \\
\hline
\end{tabular}

The use of HAs before the start of physical activity led to the maintenance of the level of lactate in the blood (Table 3 ) at the level of reference values.

Table 3. The effect of HAs on serum lactate levels

\begin{tabular}{lcccc}
\hline Group of animals & Intact & Control group No 1 & Control group No 2 & Experimental group \\
\hline Lactate level $(\mathrm{mmol} / \mathrm{l})$ & 3.7 & 4.5 & 3.1 & 3.5 \\
\hline
\end{tabular}

